\title{
Anthropometric clinical indicators of visceral adiposity as predictors of nonalcoholic fatty liver disease
}

\author{
Naiade Silveira Almeida1* (1), Raquel Rocha1 (1), Carla Daltro² (1), \\ Claudineia Almeida de Souza ${ }^{2}$ (D) Rafael Leiróz Pereira Duarte Silva² (1), \\ Manoel Alfredo Curvelo Sarno ${ }^{3}$ (D), Helma Pinchemel Cotrim³ ${ }^{3}$
}

\begin{abstract}
SUMMARY
OBJECTIVE: This study aims to evaluate the role of anthropometric clinical indicators of visceral adiposity as predictors of NAFLD, identifying the cutoff points based on gender.

METHODS: This was a cross-sectional study conducted in patients with or without NAFLD. Waist circumference (WC), body mass index (BMI), waist-to-height ratio (WHtR), Conicity Index (C Index), and lipid accumulation product (LAP) were evaluated.

RESULTS: A total of 107 individuals were evaluated, of which $46.7 \%$ were diagnosed with NAFLD. Individuals with NAFLD presented higher values of WC, BMI, C Index, LAP, and WHtR when compared with those without NAFLD ( $p<0.05)$. For the total sample, the indicators WC, BMI, WHtR, LAP, and C Index had an area under the receiver operator characteristic curve (AUC) above 0.87 , with no difference in the prediction of NAFLD in both sexes. WHtR (AUC $=0.934)$ was the indicator of visceral adiposity with the best discriminatory power for NAFLD, followed by LAP (0.919), WC (0.912), C Index (0.907), and BMI (0.877).

CONCLUSIONS: The anthropometric clinical indicators of visceral adiposity showed high performance, especially the WHtR indicator, as NAFLD predictors.

KEYWORDS: Anthropometry. Non-alcoholic fatty liver disease. Adiposity. Health status indicators. Abdominal fat. Adult.
\end{abstract}

\section{INTRODUCTION}

Nonalcoholic fatty liver disease (NAFLD) is a clinicopathological condition characterized by histopathological changes, involving abnormal accumulation of lipid in the cytoplasm of hepatocytes, especially triglycerides, in individuals with no history of excessive ethanol consumption ${ }^{1}$.

The occurrence of NAFLD is strongly related to obesity, insulin resistance (IR), and other components of the metabolic syndrome $(\mathrm{MS})^{2}$. Studies indicate that abdominal obesity, especially the accumulation of visceral fat, is closely related to the severity of the disease and hepatic steatosis ${ }^{3-6}$.
Currently, anthropometric clinical indicators such as waistto-height ratio (WHtR), lipid accumulation product (LAP), and Conicity Index (C Index) are described in the literature as more sensitive and specific to discriminate visceral fat, when compared to classical parameters such as waist circumference (WC) and body mass index (BMI) ${ }^{7}$.

However, few studies have evaluated the predictive capacity as well as the cutoff points of these new indicators in NAFLD ${ }^{8-}$ ${ }^{11}$. The objective of this study is to evaluate the role of anthropometric clinical indicators of visceral adiposity in the prediction of NAFLD, identifying the cutoff points based on gender.

\footnotetext{
'Universidade Federal da Bahia, Escola de Nutrição, Departamento de Ciências da Nutrição - Salvador (BA), Brazil.

Universidade Federal da Bahia, Programa de Pós-Graduação em Medicina e Saúde -Salvador (BA), Brazil.

3Universidade Federal da Bahia, Faculdade de Medicina da Bahia - Salvador (BA), Brazil.

*Corresponding author: naiade.silveira@hotmail.com

Conflicts of interest: the authors declare there is no conflicts of interest. Funding: none.

Received on August 22, 2021. Accepted on August 24, 2021.
} 


\section{METHODS}

\section{Study design and population}

A cross-sectional study conducted at an outpatient clinic specialized in NAFLD, Nonalcoholic Steatohepatitis (NASH) Outpatient Clinic at the Universitary Hospital - Bahia Federal University, Brazil, between April 2015 and August 2017. Inclusion criteria were individuals of both sexes, aged $>18$ years and $<60$ years, and the presence or absence of NAFLD confirmed by abdominal ultrasonography (US),

Patients with a previous diagnosis of steatosis who followed up at the clinic were taken as study group and voluntary individuals without steatosis as comparison group.

In both the groups, individuals with ingestion above 140 $\mathrm{g}$ ethanol/week, diagnosis of hypothyroidism, other chronic liver diseases (e.g., hepatitis A, B, and C; autoimmune diseases; Wilson's disease; and hemochromatosis); pregnant or lactating women; those with hepatomegaly or splenomegaly, ascites, abdominal tumors, and recent abdominal surgeries; or any physical limitation that compromised the anthropometric evaluation were not included in the study.

\section{Hepatic ultrasonography}

Abdominal US was performed by a single evaluator to measure intrahepatic fat.

\section{Laboratory evaluation}

No biochemical tests were performed, but we evaluated serum triglyceride (TG) values from test results within 3 months of the patient's assessment date.

\section{Anthropometric clinical indicators}

The anthropometric measures were calculated in duplicate by a well-trained and standardized team. Body weight $(\mathrm{kg})$, height $(\mathrm{cm})$, and WC $(\mathrm{cm})$ were measured ${ }^{12,13}$. These variables measurements were carried out according to the techniques proposed by Lohman et al. ${ }^{12}$ and the World Health Organization ${ }^{13}$.

The WHtR was calculated as WC (cm) divided by height $(\mathrm{cm})$, and the BMI was calculated by weight $(\mathrm{kg})$ divided by height $\left(\mathrm{m}^{2}\right)$.

The $C$ Index was given using the equation proposed by Valdez ${ }^{14}$ :

$\mathrm{C}$ Index $=\mathrm{WC} / 0.109 \times \sqrt{ }$ (weight/height)

The LAP was obtained using formula proposed by $\mathrm{Kahn}^{15}$ : For males,

$\mathrm{LAP}=(\mathrm{WC}[\mathrm{cm}]-65) \times($ triglyceride concentration $[\mathrm{mmol} / \mathrm{L}])$

For females,

$\mathrm{LAP}=(\mathrm{WC}[\mathrm{cm}]-58) \times($ triglyceride concentration $[\mathrm{mmol} / \mathrm{L}])$

\section{Statistical analysis}

Data were expressed as absolute and relative frequency for the categorical variables and as median and interquartile range for non-normally distributed variables. For comparison of continuous variables between the two groups, the Mann-Whitney test and Pearson's chi-square test were used.

To evaluate the performance of anthropometric clinical indicators in the prediction of NAFLD, the receiver operator characteristic (ROC) curve was used. The areas under ROC curves (AUC) and confidence intervals $(95 \% \mathrm{CI})$ were used to determine the positive predictive value (PPV), negative predictive value (NPV), and accuracy. The values of specificity, sensitivity, and Youden's Index were used to determine the optimal cutoff point.

For statistical analysis, the SPSS version 20.0 software program was used. A p-value $<0.05$ was considered statistically significant. The power of the test was based on sample size calculation method for nonparametric Wilcoxon-MannWhitney test, resulting in a higher power test of $80 \%$, prevalence of control group with BMI above normal by $48 \%$, and prevalence of case group with BMI above normal by $90 \%$ $(\mathrm{t}=0.53 ; \alpha=0.05)$.

\section{RESULTS}

A total of 107 individuals were evaluated, of which $46.7 \%$ were diagnosed with NAFLD. There was a predominance of the female gender among the individuals with NAFLD (68.0\%), while in the comparison group, there was a predominance of the male gender $(54.4 \%)(\mathrm{p}<0.05)$. There was no difference in the median age of the individuals with NAFLD and the comparison group $(\mathrm{p}<0.05)$. Based on the WC, BMI, C Index, LAP, and WHtR scores, it was observed that individuals with NAFLD presented higher values than those without the disease $(\mathrm{p}<0.05)$ (Table 1$)$.

It was found that the anthropometric indicators showed AUC above 0.87 , with no difference in the prediction of NAFLD in both sexes (Figure 1).

The WC, WHtR, LAP, and C Index presented higher values of the Youden's Index relative to BMI. When analyzed by gender, it was observed that only WC, WHtR, and LAP showed the highest values of the Youden's Index in both sexes (Table 2).

The PPV was above 0.8 for all indicators of visceral adiposity, meaning more than $80 \%$ of the patients are diagnosed with NAFLD, with BMI of 0.68. The NPV was above 0.9 for WC, WHtR, and BMI and above 0.8 for LAP and C Index, meaning that more than $80 \%$ of the patients are without NAFLD (Table 2). 


\section{DISCUSSION}

In this study, the anthropometric clinical indicators of visceral adiposity such as WC, C Index, WHtR, BMI, and LAP showed a high predictive capacity for NAFLD. Few studies have evidenced the indicators (WC, WHtR, BMI, and LAP) as more specific and sensitive in the prediction of NAFLD ${ }^{8,9,16,17}$.

Overweight and obesity are closely related to the increase in the prevalence of NAFLD, and visceral obesity is considered the most important predictor of the occurrence of NAFLD ${ }^{18}$. Visceral adipose tissue has a greater influence on metabolic disorders due to the production of adipokines that induce IR, type 2 diabetes mellitus, and hypertriglyceridemia ${ }^{19,20}$, which predispose the occurrence of NAFLD. Anthropometric indicators such as BMI and WC are widely used in the evaluation of patients with NAFLD, and several studies have shown an association of these indicators with steatosis and $\mathrm{NASH}^{3,6,8}$. However, it is important to emphasize on the limited use of $\mathrm{BMI}$ in the evaluation of the distribution and body composition, not allowing to distinguish between central obesity $^{21}$, and this type of obesity seems to be an important risk factor for NAFLD, even in those individuals with normal BMI ${ }^{22}$.

Despite our optimal cutoff point for WC similar to those suggested by the International Diabetes Federation ${ }^{23}$ for the diagnosis of MS, Ju et al. ${ }^{10}$ identified other cutoff points, showing that there is still controversy over the best anthropometric parameter to predict NAFLD.

Table 1. Demographic characteristics and anthropometric clinical indicators of visceral adiposity of individuals with and without nonalcoholic fatty liver disease.

\begin{tabular}{|c|c|c|c|}
\hline Variable & $\begin{array}{l}\text { NAFLD } \\
(n=50)\end{array}$ & $\begin{array}{c}\text { Comparison } \\
\text { group } \\
(\mathrm{n}=57)\end{array}$ & $p$ \\
\hline \multicolumn{4}{|l|}{ Sex, n (\%) } \\
\hline Female & $34.0(68.0)$ & $26.0(45.6)$ & \multirow{2}{*}{$0.02^{*}$} \\
\hline Male & $16.0(32.0)$ & $31.0(54.4)$ & \\
\hline Age (years) $)^{\dagger}$ & $\begin{array}{c}48.5 \\
(39.0-55.0)\end{array}$ & $\begin{array}{c}32.0 \\
(28.0-36.5)\end{array}$ & $<0.01^{\ddagger}$ \\
\hline$W C(\mathrm{~cm})^{\dagger}$ & $\begin{array}{c}97.7 \\
(91.0-107.1)\end{array}$ & $\begin{array}{c}78.0 \\
(71.5-85.0)\end{array}$ & $<0.01^{\ddagger}$ \\
\hline $\mathrm{BMI}\left(\mathrm{kg} / \mathrm{m}^{2}\right)^{\dagger}$ & $\begin{array}{c}30.1 \\
(27.1-33.8)\end{array}$ & $\begin{array}{c}24.0 \\
(22.4-26.2)\end{array}$ & $<0.01^{\ddagger}$ \\
\hline C Index ${ }^{\dagger}$ & $1.2(1.2-1.3)$ & $1.1(1.0-1.1)$ & $<0.01^{\neq}$ \\
\hline $\mathrm{LAP}^{+}$ & $\begin{array}{c}61.1 \\
(40.6-85.7)\end{array}$ & $\begin{array}{c}14.1 \\
(9.2-24.2)\end{array}$ & $<0.01^{\ddagger}$ \\
\hline $\mathrm{WHtR}^{+}$ & $0.6(0.5-0.6)$ & $0.4(0.4-0.5)$ & $<0.01^{\ddagger}$ \\
\hline
\end{tabular}

NAFLD: nonalcoholic fatty liver disease; WC: waist circumference; BMI: Body Mass Index; C Index: conicity index; LAP: lipid accumulation product; WHtR: waist-to-height ratio. *Pearson's chi-square test; ${ }^{+}$Results presented in Median and Interquartile range; ${ }^{\prime}$ Mann-Whitney test.

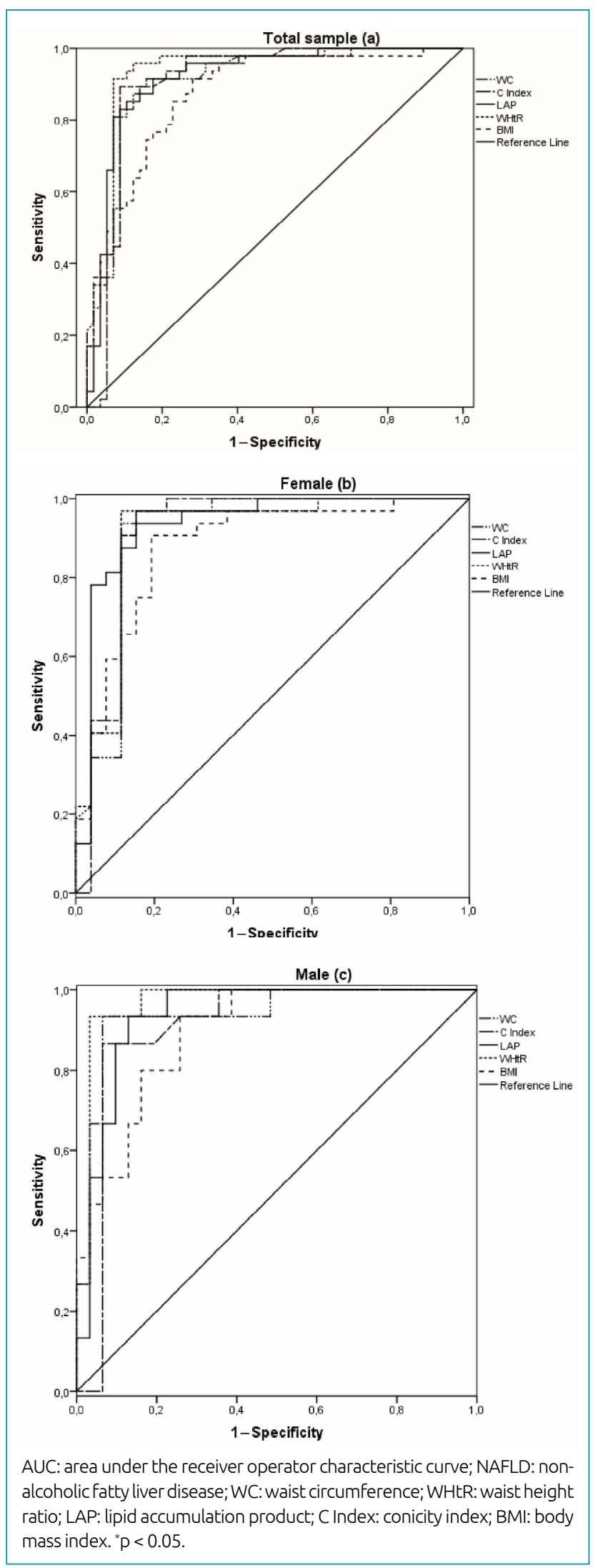

Figure 1. Receiver operator characteristic analysis with areas under the curve of the anthropometric clinical indicators in the prediction of nonalcoholic fatty liver disease by sex. 
Zheng et al. ${ }^{9}$ found that $\mathrm{WHtR}$ presented greater discriminatory power for NAFLD in relation to BMI. However, if both WC and WHtR have similar discriminatory power, NAFLD was better discriminated by waist-to-hip ratio.

The divergences between the cutoff points of the $\mathrm{WHtR}$ for the prediction of NAFLD could be related to the age and ethnicity of the individuals ${ }^{17}$. In the Iranian study ${ }^{11}$, the sample composed of individuals over 60 years of age, different from our study that did not include the elderly. Thus, it should be noted that there are changes in body composition with the aging process, which could generate different $\mathrm{WHtR}$ cutoffs by age group.

LAP was identified to have a good discriminatory capacity for NAFLD ${ }^{8,16}$. The LAP is an indicator that evaluates if the concentration of lipids exerts an effect in the evaluation of the cardiovascular risks and is considered better than the $\mathrm{BMI}^{15}$.

In the literature, studies conducted with the C Index specifically in NAFLD have not been found, which makes this study the first to evaluate the predictive capacity. C Index has been considered as one of the most accurate indicators in the discrimination of visceral obesity, in relation to other anthropometric clinical indicators of visceral fat in the adult population $^{7}$, and also as a good predictor of high coronary risk ${ }^{24}$ and cardiovascular risk ${ }^{7,25}$ factors that are related to the occurrence of NAFLD. The C Index incorporates three easy-to-measure anthropometric measures, including WC, which is common to the other indicators of visceral adiposity.

It should be emphasized that although LAP and C Index presented good performance, the clinical use of these indicators may be limited, since serum levels of TG and use of specific formula are required. Anthropometric indicators (BMI, WC, and $\mathrm{WHtR}$ ) are easy to perform, indicating a positive factor for clinical applicability.

The main benefits of this study include the evaluation of several anthropometric indicators in the prediction of NAFLD in a single sample; the evaluation of the $\mathrm{C}$ Index; and a pioneering study in the literature in the population with NAFLD. However, our study had some limitations. First, the number of individuals evaluated in this work. Thus, studies with larger sample groups would be important to better analyze the

Table 2. Cutoff points, Youden's Index, sensitivity, specificity, positive predictive value and negative predictive value, and accuracy of anthropometric clinical indicators in the prediction of nonalcoholic fatty liver disease.

\begin{tabular}{|c|c|c|c|c|c|c|c|}
\hline Indicator & Cutoff & Youden's Index & Sensitivity (\%) & Specificity (\%) & PPV & NPV & Accuracy \\
\hline \multicolumn{8}{|l|}{ WC } \\
\hline Sample & 86.7 & 0.74 & 87 & 87 & 0.87 & 0.94 & 0.90 \\
\hline Male & 90.1 & 0.86 & 93 & 93 & 0.87 & 0.93 & 0.91 \\
\hline Female & 82.5 & 0.81 & 93 & 88 & 0.86 & 0.95 & 0.90 \\
\hline \multicolumn{8}{|l|}{ WHtR } \\
\hline Sample & 0.5 & 0.82 & 95 & 87 & 0.82 & 0.95 & 0.88 \\
\hline Male & 0.5 & 0.80 & 93 & 87 & 0.75 & 0.96 & 0.87 \\
\hline Female & 0.5 & 0.84 & 96 & 88 & 0.86 & 0.95 & 0.90 \\
\hline \multicolumn{8}{|l|}{ LAP } \\
\hline Sample & 26.7 & 0.83 & 91 & 82 & 0.89 & 0.81 & 0.84 \\
\hline Male & 32.7 & 0.80 & 93 & 87 & 0.81 & 0.82 & 0.82 \\
\hline Female & 23.3 & 0.77 & 93 & 84 & 0.92 & 0.80 & 0.86 \\
\hline \multicolumn{8}{|l|}{ C Index } \\
\hline Sample & 1.2 & 0.79 & 89 & 91 & 0.88 & 0.83 & 0.85 \\
\hline Male & 1.1 & 0.66 & 86 & 80 & 0.81 & 0.82 & 0.82 \\
\hline Female & 1.1 & 0.78 & 90 & 88 & 0.90 & 0.85 & 0.88 \\
\hline \multicolumn{8}{|l|}{ BMI } \\
\hline Sample & 26.7 & 0.56 & 78 & 78 & 0.68 & 0.94 & 0.77 \\
\hline Male & 27.3 & 0.63 & 80 & 83 & 0.53 & 1.00 & 0.70 \\
\hline Female & 25.9 & 0.67 & 87 & 80 & 0.80 & 0.90 & 0.83 \\
\hline
\end{tabular}

PPV: positive predictive value; NPV: negative predictive value; WC: waist circumference; WHtR: waist-to-height ratio; LAP: lipid accumulation product; C Index: conicity index; BMI: body mass index. 
prediction and cutoff points of visceral adiposity indicators by sex in individuals with NAFLD. Second, the median age of the two groups is different. Third, the diagnosis of hepatic steatosis was confirmed by US, a method that has significant limitations, since individuals with normal US may still have NAFLD.

\section{CONCLUSIONS}

The anthropometric clinical indicators of visceral adiposity showed high performance, especially WHtR, as NAFLD predictor. Based on the results of this study, we can conclude that indicators of visceral adiposity, also BMI, play a role to the diagnosis of NAFLD and can be used in the clinical evaluation of individuals who are at risk of NAFLD, allowing clinical intervention and consequently early nutritional intervention, as well as the monitoring of these individuals.

\section{ACKNOWLEDGMENTS}

The authors thank the Foundation for Research Support of the State of Bahia (FAPESB) and the Coordination for the Improvement of Higher Education Personnel (CAPES).

\section{ETHICAL STATEMENT}

The authors are accountable for all aspects of the work in ensuring that questions related to the accuracy or integrity of any part of the work are appropriately investigated and resolved.
The study was approved by the research ethics committee of the School of Nutrition of the Federal University of Bahia (Opinion $\mathrm{n}^{\circ}$ 774.353/2014). Informed consent was obtained from all participants. The research was conducted ethically in accordance with the World Medical Association Declaration of Helsinki (https://www.wma.net/policies-post/wma-declaration-of-helsinki-ethical-principles-for-medical-research-involving-human-subjects/).

\section{AUTHORS" CONTRIBUTIONS}

NSA: Conceptualization, Data curation, Formal analysis, Investigation, Methodology, Project administration, Resources, Supervision, Validation, Visualization, Writing - original draft, Writing - review \& editing. RR: Conceptualization, Data curation, Formal analysis, Investigation, Methodology, Project administration, Resources, Supervision, Validation, Visualization, Writing - original draft, Writing - review \& editing. CD: Conceptualization, Data curation, Formal analysis, Investigation, Methodology, Project administration, Resources, Supervision, Validation, Visualization, Writing - original draft, Writing - review \& editing. CAS: Data curation, Project administration, Resources, Supervision, Validation. RLPDS: Data curation, Investigation, Methodology, Project administration. MACS: Data curation, Project administration. HPC: Conceptualization, Formal analysis, Investigation, Methodology, Project administration, Resources, Supervision, Writing - original draft, Writing - review \& editing.

\section{REFERENCES}

1. Arteaga I, Buezo I, Expósito C, Pera G, Rodríguez L, Alumà A, et al. Marcadores no invasivos de fibrosis en el diagnóstico del hígado graso no alcohólico. Gastroenterología y Hepatología. 2014;37(9):50310. https://doi.org/10.1016/j.gastrohep.2014.03.009

2. Moore JB. Non-alcoholic fatty liver disease: the hepatic consequence of obesity and the metabolic syndrome. Proc Nutr Soc. 2010;69(2):211-20. https://doi.org/10.1017/ S0029665110000030

3. Rocha R, Cotrim HP, Carvalho FM, Siqueira AC, Braga H, Freitas LA. Body mass index and waist circumference in non-alcoholic fatty liver disease. J Hum Nutr Diet. 2005;18(5):365-70. https:// doi.org/10.1111/j.1365-277X.2005.00634.x

4. Eguchi $Y$, Eguchi T, Mizuta T, Ide $Y$, Yasutake T, Iwakiri R, et al. Visceral fat accumulation and insulin resistance are important factors in nonalcoholic fatty liver disease. J Gastroenterol. 2006;41(5):462-9. https://doi.org/10.1007/s00535-006-1790-5

5. van der Poorten D, Milner KL, Hui J, Hodge A, Trenell MI, Kench JG, et al. Visceral fat: a key mediator of steatohepatitis in metabolic liver disease. Hepatology. 2008;48(2):449-57. https://doi.org/10.1002/hep.22350
6. Aller R, Izaola O, Ruiz-Rebollo L, Pacheco D, Luis DA. Predictive factors of non-alcoholic steatohepatitis: relationship with metabolic syndrome. Nutr Hosp. 2015;31(6):2496-502. https:// doi.org/10.3305/nh.2015.31.6.8908

7. Roriz AKC, Passos LCS, Oliveira CC, Eickemberg M, Moreira PA, Sampaio LR. Evaluation of the accuracy of anthropometric clinical indicators of visceral fat in adults and elderly. PLoS One. 2014;9(7):e103499. https://doi.org/10.1371/journal. pone.0103499

8. Cuthbertson DJ, Weickert MO, Lythgoe D, Sprung VS, Dobson $\mathrm{R}$, Shoajee-Moradie $\mathrm{F}$, et al. External validation of the fatty liver index and lipid accumulation product indices, using $1 \mathrm{H}$-magnetic resonance spectroscopy, to identify hepatic steatosis in healthy controls and obese, insulin-resistant individuals. Eur J Endocrinol. 2014;171(5):561-9. https://doi org/10.1530/EJE-14-0112

9. Zheng RD, Chen ZR, Chen JN, Lu YH, Chen J. Role of body mass index, waist-to height and waist to-hip ratio in prediction of nonalcoholic fatty liver disease. Gastroenterol Res Pract. 2012;2012:362147. https://doi.org/10.1155/2012/362147 
10. Ju DY, Choe YG, Cho YK, Shin DS, Yoo SH, Yim SH, et al. The influence of waist circumference on insulin resistance and nonalcoholic fatty liver disease in apparently healthy Korean adults. Clin Mol Hepatol. 2013;19(2):140-7. https:// doi.org/10.3350/cmh.2013.19.2.140

11. Motamed N, Rabiee B, Hemasi GR, Ajdarkosh H, Khonsari MR, Maadi $\mathrm{M}$, et al. Body roundness index and waist-to-height ratio are strongly associated with non-alcoholic fatty liver disease: a population-based study. Hepat Mon. 2016;16(9):e39575. https://doi.org/10.5812/hepatmon.39575

12. Lohman TG, Roche AF, Martorell R. Anthropometric standardization reference manual. Illinois: Human Kinetics Books; 1988.

13. World Health Organization. Obesity: preventing and managing the global epidemic: report of a WHO consultation. WHO Technical Report Series. Geneva: World Health Organization; 2000.

14. Valdez RA. Simple model-based index of abdominal adiposity. J Clin Epidemiol. 1991;44(9):955-6. https://doi. org/10.1016/0895-4356(91)90059-i

15. Kahn HS. The "lipid accumulation product" performs better than the body mass index for recognizing cardiovascular risk: a population-based comparison. BMC Cardiovasc Disord. 2005;5:26. https://doi.org/10.1186/1471-2261-5-26

16. Bedogni G, Kahn HS, Bellentani S, Tiribelli C. A simple index of lipid overaccumulation is a good marker of liver steatosis. BMC Gastroenterol. 2010;10:98. https://doi.org/10.1186/1471230X-10-98

17. Singh A, Parida S, Narayan J, Nath P, Padhi PK, Pati GK, et al. Simple anthropometric indices are useful for predicting non-alcoholic fatty liver disease [NAFLD] in Asian Indians. J Clin Exp Hepatol. 2017;7(4):310-5. https://doi.org/10.1016/j. jceh.2017.05.005
18. Kim D, Chung GE, Kwak MS, Seo HB, Kang JH, Kim W, et al. Body fat distribution and risk of incident and regressed nonalcoholic fatty liver disease. J Gastroenterol Hepatol. 2016;14(1):132-8. e4. https://doi.org/10.1016/j.cgh.2015.07.024

19. Vazquez G, Duval S, Jacobs Jr DR, Silventoinen K. Comparison of body mass index, waist circumference, and waist/hip ratio in predicting incident diabetes: a meta-analysis. Epidemiol Rev. 2007;29:115-28. https://doi.org/10.1093/epirev/mxm008

20. Decoda Study Group, Nyamdorj R, Qiao Q, Lam TH, Tuomilehto J, Ho SY, et al. BMI compared with central obesity indicators in relation to diabetes and hypertension in Asians. Obesity (Silver Spring). 2008;16(7):1622-35. https://doi.org/10.1038/oby.2008.73

21. Le Bian AZ, Costi R, Constantinides V, Smadja C. Metabolic disorders, non-alcoholic fatty liver disease and major liver resection: an underestimated perioperative risk. J Gastrointest Surg. 2012;16(12):2247-55. https://doi.org/10.1007/s11605-012-2044-x

22. Fan JG, Zhu J, Li XJ, Chen L, Li L, Dai F, et al. Prevalence of and risk factors for fatty liver in a general population of Shanghai, China. J Hepatol. 2005;43(3):508-14. https://doi. org/10.1016/j.jhep.2005.02.042

23. Alberti KGMM, Zimmet $P$, Shaw J. Metabolic syndrome - a new world-wide definition. A Consensus Statement from the International Diabetes Federation. Diabet Med. 2006;23(5):46980. https://doi.org/10.1111/j.1464-5491.2006.01858.x

24. Pitanga FJG, Lessa, I. Sensibilidade e especificidade do índice de conicidade como discriminador do risco coronariano de adultos em Salvador, Brasil. Rev Bras Epidemiol. 2004;7(3):25969. https://doi.org/10.1590/S1415-790X2004000300004

25. Vidigal FC, Rosado LEFPL, Rosado GP, Ribeiro RCL, Franceschini SCC, Priore SE, et al. Predictive ability of the anthropometric and body composition indicators for detecting changes in inflammatory biomarkers. Nutr Hosp. 2013;28(5):1639-45. https://doi.org/10.3305/nh.2013.28.5.6743 